\section{THE METALLOGRAPHY OF IRON AND} IRON-CARBON ALLOYS.

$A^{T}$ the May meeting of the Iron and Steel Institute two papers of decided scientific importance were presented. In one of these Prof. G. Cesarò, of Liège University, a distinguished Belgian man of science, has endeavoured by careful mathematical analysis to ascertain the course of the curve joining the points at which molten iron-carbon alloys commence to solidify, if the abscissæ are taken either as $x$, the number of atoms of carbon contained in a unit of the allny, composed of a hundred atoms, or as $y$, the number of molecules of cementite $\mathrm{Fe}_{3} \mathrm{C}$ contained in a unit of the alloy composed of a hundred molecules, and assuming an iron molecule to contain two atoms. The author has used for his data the experimental results obtained by Carpenter and Keeling fifteen years ago, which are generally accepted as valid for the liquidus of the series. He comes to the conclusion that whether Raoult's law of the depression of the freezing point or the more general law expressed by the Le ChatelierSchroeder formula

$$
l s=\frac{\mathrm{Q}}{2}\left(\begin{array}{c}
\mathrm{I} \\
\mathrm{Y}
\end{array}-\frac{\mathrm{J}}{\mathrm{i}}\right),
$$

where $T$ is the absolute temperature and $z$ is the number of molecules in the solvent contained in a unit of the alloy forming a single molecule, be adopted, the calculated figures agree, decidedly better with the experimental results on the iron-cementite than the ironcarbon hypothesis. Further, the results which agree best are obtained on the assumption of a rectilinear variation afforded by the $\mathrm{Fe}_{3} \mathrm{C}-\mathrm{Fe}_{2}$ hypothesis.

In the second paper Prof. Honda, of the Toholsu Imperial University, Sendai, Japan, returns to a consideration of the allotropic forms of iron. It is now generally agreed that pure iron undergoes two transformations between the freezing point and the ordinary temperature, which are allotropic. The first of these is the $\mathrm{A}_{4}$ transformation, and takes place at $\mathrm{I} 394^{\circ} \mathrm{C}$., about $130^{\circ}$ below the freezing point. It is completed in a few minutes. The second is the $A_{3}$ transformation, and occurs at about $900^{\circ} \mathrm{C}$. This transformation, although not so rapid as the previous one, can be completed in a very narrow temperature interval, provided the heating and cooling are sufficiently slow. In a recent experiment by Ishiwara, where the complete transformation required about three hours, the difference between the $\mathrm{Ac}_{3}$ and $\mathrm{Ar}_{3}$ points did not exceed $5^{\circ} \mathrm{C}$.

The $A_{2}$ change is of a different nature. It does not take place at a definite temperature or within a small range, but begins at the ordinary temperature, its rate becoming greater as the temperature is increased, until it is completed at $785^{\circ} \mathrm{C}$. The various physical properties, such as heat absorption or evolution, intensity of magnetisation, electrical resistance, thermal conductivity, etc., vary similarly with one another, the values changing slowly at lower temperatures, and the change becoming faster as the temperatures approach $78_{5}^{\circ} \mathrm{C}$. When thermal equilibrium is established the change in any one of the properties does not increase by a prolonged heating. The properties are definite functions of the temperatures. It is this distinction. according to the author. which constitutes the essential difference between allotropic and non-allotropic changes. According to him, therefore, an allotropic change is the transformation of a substance from one phase to another which proceeds at a definite temperature if sufficient time be allowed for the transformation.

The $\mathrm{A}_{2}$ critical point, as determined thermally, is usually taken as $768^{\circ} \mathrm{C}$. This is the temperature at which the rate of heat evolution or absorption is at No. 2596, VOL. TO3] the maximum on cooling and heating respectively. This figure is somewhat lower than $785^{\circ} \mathrm{C}$., which is the value proposed by Honda, and is the temperature at which the $\mathrm{A}_{2}$ transformation begins on cooling and terminates on heating.

In the case of carbon steels, in addition to the above, there are two other transformations, $A_{1}$ and $A_{0}$. The former is a change of phase, while the latter is a change in cementite of a similar nature to $A_{2}$. Accordingly, whereas $A_{4}, A_{3}$, and $A_{1}$ are phase changes, the $A_{2}$ and $A_{0}$ transformations extend from the critical to the lowest temperature. Every stage of these changes is a definite function of the temperature, and, from the point of view of the molecular theory of magnetism, they may be regarded as processes in which the molecules acquire rotational energy about their magnetic axes.

\section{H. C. H. Carpenter.}

\section{SEX, REPRODUCTION, AND HEREDITY IN PIGEONS AND FOWLS.}

$\mathrm{D}^{\mathrm{R}}$. OSCAR RIDDLE has previously brought forward evidence to show that male pigeons arise from eggs (yolks) of less storage metabolism, which implies small size and higher (oxidising) metabolism, and that females arise from eggs (yolks) of greater storage metabolism, which implies large size and lower (oxidising) metabolism. He has now (Journ. Exper. Zoology, vol. xxvi., I9I8, pp. 227-54) studied two cases of female "identical twins," and seeks to show that the ova (yolks) which produced both of them were extraordinarily and atnormally large.

Of course, the yolk of an egg cannot be directly weighed on a balance and then put back to see what it will develop into; Dr. Riddle's evidence is necessarily indirect. The eggs when laid were very large compared with all the other eggs produced by the particular parents (totals of 116 and I34 eggs). Double-yolked eggs in doves are practically restricted in their production to hybrids from wider crosses, or to birds showing striking reproductive abnormalities, or to both of these, and would not be expected to appear in the series in which the two cases of "identical twins" were found.

It is suggested that the blastoderm-borders will be abnormally raised in extraordinarily large eggs, and abnormally lowered in extraordinarily small ones, and that this might lead, for physical reasons; to the establishmerit of two independent foci of development. If male "identical twins" were found developing from a very small egg. it would be an interesting corroboration of the author's theory. Meanwhile, he thinks that the available data point to the conclusion that each pair of female "identical twins" arose from a single ovum of high storage metabolism.

In healthy doves and pigeons the right testis is larger than the left in a very high percentage of cases, vet in the female it is the left ovary that persists. The left testis more nearly approaches the ovary than does the right. In disease, particularly in tuberculosis, the testes undergo extreme atrophy, but more in the right than in the left; the ova:y does not seem to suffer reduction in size. The right testis of the very voung birds (from embrvos to squabs a few weeks old) is normally longer than the left. The single (persistent) left ovary of voung female squabs is twice, or more than twice, as long as is either testis in males of similar age (three to seven weeks). Now Dr. Riddle finds (Anat. Record, vol. xiv., Iq 8 , pp. $28_{3-}$ 3.34) that in hybrids the normal size relations of the two testes are often disturbed, sometimes reversed, approximating to the female condition. The number 